\title{
Navas e Gumbrecht: convergências na Presença ${ }^{1}$
}

Navas and Gumbrecht: Convergence in the Presence

Cristina Santaella Braga

é bailarina, formada em psicologia, mestra na pós-

1.

crisantaella@yahoo.com.br

graduação do Instituto de Artes da Unicamp e

doutoranda nesse mesmo programa de pós-graduação,

sob orientação da Profa Dra ${ }^{a}$. Cássia Navas.

Resumo

Este ensaio visa um diálogo entre dois importantes teóricos, Gumbrecht e Navas, tendo como pontos nodais a reflexão entre o livro de Gumbrecht (1948), A Produção da Presença: o que o sentido não consegue transmitir e dois textos de Cássia Navas, Do intimo, do particular e o público: subsídios para a gestão em dança (2009) e Permanente e efêmero, questões e um exemplo da recepção em dança (2013).

Palavras-chave: sentido, presença, corpo e espetáculo.

\section{Abstract}

This test is a dialogue between two important theoretical, Gumbrecht and Navas, having as nodes the reflection between the book Gumbrecht (1948), The Production of Presence: what sense cannot transmit and two texts of Cassia Navas, The intimate, private and public: subsidies for management in dance (2009) and Permanent and ephemeral issues and an example of the reception dance (2013).

Keywords: sense, presence, body and spectacle. 
A princípio seria um artigo. Do artigo migrou ensaio. Do ensaio para a cena. Do corpo à escrita, não se trata aqui de um mesmo treinamento ao dar-se no desnudar-se à presença?

A atividade particular é velada e escapa à maior parte do público e mesmo a outros profissionais da cultura/arte...

Os esforços para trazer o íntimo até o público não se revelam abertamente. Treinamento dia-após-dia, luta corporal interna de superação de limites de si, estratégias heterodoxas de sobrevivência, não se dão a ver abertamente ao público, que mais quer saber da magia desta intimidade revelada, transposta em linguagem potente e metafórica a cada apresentação. (Navas, 2009, p. 5,6)

O caminho percorrido por Gumbrecht para texturizar a presença em palavras segue uma rota muito dinâmica e interessante em seu livro de 1948 cujo título leva o nome de a Produção de Presença: o que o sentido não consegue transmitir. Porque o desejo de convergir essa fala, presença, nas reflexões desenvolvidas pelo autor junto às colocações de Navas em: Do íntimo, do particular e o público: subsídios para a gestão em dança (2009) e Permanente e efêmero, questões e um exemplo da recepção em dança (2013)? Por algumas razões. O tema que nos parece ultrapassado é muito atual. O tema tão falado é pouco debatido. A forma como o autor nos conduz em sua reflexão, faz de seu texto uma rede de palavras-presença, sentido capturado na narrativa presente-presença. E, algo dessa presença nos textos a serem discutidos, acadêmicos, faz sensação-palavra e não mais somente sensação-livro. Essa ludicidade, insistente encontro à presença, tema este tão recorrente nas artes da cena, e, ainda tão poroso quando em contato com a escrita, mostra que, essa presença que aqui tento re-colocar, quando em contato com o universo da dança, em especial àqueles que vêem da prática, se revela frágil e de uma captura sempre desviante com o seu leitor. Por isso, a importância de trazer para esse encontro esses dois autores que farão dessa reflexão um momento de presença-escrita. Ainda que direcionados a uma leitura do sentido, a presença da narrativa de Gumbrecht aliada à sonoridade poética de Navas faz a presença, um imperativo. O sentido como borda. A escrita como possibilidade coreográfica de uma dança em palavras presença.

Nessa trilha, quase como modelo de romance, o autor traça um permanente diálogo crítico com diversas áreas das ciências humanas, a teoria literária, a historiografia e a filosofia, buscando alternativas epistemológicas ao que denuncia como "o predomínio praticamente absoluto e injustificado da autocompreensão das humanidades" como saberes cuja tarefa exclusiva é extrair ou atribuir sentido aos fenômenos que analisa. (Gumbrecht, 1948, p.8).

$\mathrm{O}$ autor pensa a presença, em primeiro lugar, às coisas que 
estando à nossa frente, ocupam espaço, são tangíveis aos nossos corpos e não são apreensíveis, estritamente por uma relação de sentido. Pensamos para a análise da presença àquilo que podemos experimentar, primordialmente, fora da linguagem. Ora, mas numa cultura eminentemente do sentido, como lidar com essas experiências de modo não interpretativo ou não hermenêutico? Essa é justamente a questão do autor.

Para dialogar com Gumbrecht, Cássia Navas, crítica e autora das artes, mais especificamente da dança. Autora que analisa aqui questões vinculadas à permanência e efemeridade dos espetáculos, "a dança que resta em nós", buscando aqui uma descrição a partir de conteúdos que circula entre artistas da cena e público. Nada mais justo do que dividirmos o palco entre autores, que em seus escritos do sentido, potencializam a presença.

Não gostaria aqui de fazer uma mera reprodução dos textos, ato que julgo sempre entediante quando em outras leituras. Ocorre que diante dessas poéticas, não ousaria transformá-las em sentido, como a vida acadêmica nos impõe, mas coreografar com elas algo dessa remontagem sem perder de vista o original, marcado aqui por uma presença-escrita. Palavras em cena.

\footnotetext{
A dança como fenômeno de comunicação humana, pode ser vislumbrada através de espécies de molduras - os espetáculos -, onde presenciamos a vontade revelada de expressão de um artista-coreógrafo concretizadas em corpos de artistas-bailarinos. (Navas, 2013, p. 1).
}

Segundo Gumbrecht (ibid., p. 13, 32), a palavra presença não se refere a uma relação temporal. Antes, refere-se a uma relação espacial com o mundo e seus objetos. "O uso produção no sentido da sua raiz etimológica (do latim producere), que se refere ao ato de "trazer para diante" um objeto no espaço". Assim, produção de presença aponta para todos os tipos de eventos e processos nos quais se inicia ou se intensifica o impacto dos objetos presentes sobre corpos humanos. "Todos os objetos disponíveis em presença serão chamado aqui - as coisas do mundo". As "coisas do mundo" como efemeridade da obra? Poderíamos pensar a partir das reflexões de Navas (2013, p, 5,6), que a efemeridade se constrói-reconstrói, a todo momento, entre obra e público no universo das artes, se esse refazer não se instaurasse, em última instância, "de cada coreografia nada restaria”.

Neste sentido, o efêmero não está na criação em si, portadora de suas estruturas de base, guardadas e recolocadas no mundo mediante o sistema de memória - enquanto lembrança e esquecimento - que se estrutura a partir de sua origem basal, na qual se enraízam os traços de sua existência e operação (ibid., p. 5,6) 
Seguindo com a discussão, a questão central que se impôs para o autor e seus colegas era a de saber como os diferentes meios e as "diferentes materialidades de comunicação afetariam o sentido que transportavam". Pensamos na palavra presença a partir de uma referência espacial. O que é presente para nós, comumente é o que está à nossa frente, ao alcance e tangível para nossos corpos. Então, pensar "na produção de presença com as materialidades de comunicação é também um efeito em movimento permanente". Falar dessa produção implica que o efeito de tangibilidade (espacial) está sujeito a movimentos de maior ou menor proximidade e de maior ou menor intensidade. (ibid., p.39).

Após um espetáculo, tempo e espaço têm que ser reconstruídos de uma maneira singular, numa tarefa em que as grafias da dança podem ser de grande auxílio - texto, foto, vídeo e mesmo os depoimentos sobre cada dança, colhidos em entrevistas onde quase-poemas são enunciados por artistas, flagrados por palavras a respeito do conhecimento que colocam no mundo. (Navas, 2013, p.1)

Gumbrecht (ibid., p. 39) nos lembra que o prazer da presença é a fórmula mística por excelência, e uma presença que escapa à dimensão do sentido tem de estar em tensão com o princípio da representação. "A presença não vem sem apagar a presença que a representação gostaria de designar”.

Somos partícipes e cúmplices do realizado (performado), enquanto público - unidade, individualmente traçando análises ou recolhendo emoções, traços que talvez insistam em nossa memória, na forma de presença e ausência, lembrança e esquecimento. (Navas, 2013, p. 1)

A auto-referência predominante num mundo de sentido é o pensamento, ao passo que, a auto-referência predominante numa cultura de presença, é o corpo.

Numa cultura de presença, além de serem materiais, as coisas do mundo já têm por eles mesmos um sentido que lhes é inerente, e não apenas um sentido interpretativo, e os seres humanos consideram seus corpos como parte integrante da sua existência.

Numa cultura do sentido por sua vez, a legitimidade se dá se tiver sido produzido por um sujeito no ato de interpretar o mundo, campo da hermenêutica. Para uma cultura da presença, o conhecimento é legítimo se for conhecimento tipicamente revelado. Conhecimento revelado pelos deuses ou por outras variedades daquilo que se poderá "descrever como eventos de autorrevelação do mundo”. (ibid., p.106,107). 
O artista dança por nós, a cada dia em que se coloca em cena. Algumas vezes nos dança, no sentido de mostrar/ expressar/ comunicar nossos pensamentos através desta mídia onde a questão do corpo assume uma centralidade basal. (Navas, 2013, p. 7)

Para Gumbrecht (ibid., p. 109), o que mais se aproxima de um conceito de "ação" (motivação) numa cultura do sentido é, numa cultura da presença, o conceito de magia, ou seja, a prática de tornar presentes coisas que estão ausentes e ausentes coisas que estão presentes.

Para Navas (ibid., p. 3), a efemeridade está na presentificação da obra ali, naquele instante, esta característica aponta "para uma de suas bases de origem, enquanto arte do tempo/ espaço, que se perfaz em tempo específico, restando como memória corporal nos artistas que a interpretam”.

O corpo-território de cada bailarino lança-se no espaço - território da dança, este sim transitório frente a cada unidade de público, construído no aqui-e-agora a partir de traços - rastros anterior. (Navas, ibid., p.3)

Dessa forma, imaginar uma cultura de presença implica, necessariamente, o desafio de imaginar um conceito de eventidade. "Não existe emergência de sentido que não alivie o peso da presença".

Cabe aqui entendermos através de Navas (2009) o que se torna público em dança, no trânsito entre o sentido e a presença na via de mão dupla entre intérprete e público.

A intimidade de um corpo que comunica conteúdo adivinhado, a partir de uma experiência inaugural, de uma idéia em dança, tatuada no particular do corpo de cada um.

No entanto, por mais particular que seja uma situação dançada por um corpo em especial, aquele bailarino carrega consigo traços dos homens e mulheres de seu tempo e espaço e, por isto, frente a nós também está "um corpo cultural".

A adivinhação, que se revela como "experiência estética" é revelação íntima, interna, mas se dá a partir de percepções/cognições do ambiente onde cada um trafega: locais de um tempo-espaço, portanto locais de uma história.

Quando um bailarino dança, o que faz é constrangedoramente íntimo, e ao mesmo tempo, público, por sua exposição devassadamente aberta, mas também por sua dança carregar em si um bocado de conteúdos da comunidade que com ele partilha parcela do que ali se expõe. (Navas, 2009, p. 6)

Gumbrecht (ibid., p. 134-139), diz que a presença e o sentido, porém, sempre aparecem juntos e em tensão. Para nós, os fenômenos de presença surgem sempre como efeitos de presença 
porque "estão necessariamente rodeados de, embrulhados em, e talvez até mediados por nuvens e almofadas de sentido".

Sob esse ponto de vista, a experiência estética traz o confronto com a tensão e a oscilação, entre a presença e o sentido. A experiência estética, de certa maneira nos empurra o não familiar, para fora da experiência do todo dia. Atravessados por essa experiência, um furo no cotidiano e um estado outro, digamos assim, se realiza com destreza. "É experiência advinda de uma crise, de um limite e nos joga em outro estado de percepção, do qual saímos diferenciados. A experiência estética impera na vida, mas é programa, meta a ser alcançada na arte e pela arte". (Navas, 2009, p. 2)

Gumbrecht (ibid., p. 140, 142), a fim de ampliar ainda mais essa reflexão, sob o título de epifania, comenta três características que moldam a maneira como se apresenta diante de nós a tensão entre presença e sentido; nunca sabemos se ou quando ocorrerá uma epifania; não sabemos qual será a sua intensidade e a epifania na experiência estética é um evento, pois se desfaz como surge. Ora, podemos compreender o desejo de presença como reação ao todo dia que se tornou âncora de sentidos, sentido pelo sentido, mais sentido, ou se preferirem, universo predominantemente cartesiano ao longo dos últimos séculos. A experiência estética vem como uma âncora na recuperação da nossa dimensão espacial e corpórea da nossa existência, tão policiada pelo imperativo dos sentidos. Ora, "experienciar as coisas do mundo na sua coisidade pré-conceitual reativará uma sensação pela dimensão corpórea e pela dimensão espacial da nossa existência”. (Gumbrecht, 1948, p. 145-147).

Não se trata aqui de fazer uma apologia romântica ao mundo anti-cartesiano ao mundo da presença cujo comando está marcado pelo universo das sensações. É que dar sentido ao mais do sentido é perder de vista o que a arte, de modo geral tem a nos oferecer. Ora, frente a um espetáculo desabrocha uma espécie de estado cândido, poroso e desarmado, fazendo com que o nosso julgamento perceptivo fique por um momento em suspensão. O julgamento hesita e não vem. Ficamos como que tomados pela qualidade daquele momento. Não estaríamos aqui às voltas com o efeito estético?

Sim. O espectador entra num estado especial. O julgamento não vem de imediato, e o efeito da incerteza e vagueza que ocupa seu espaço. Olhamos e ficamos incertos, inclusive quanto ao efeito que está sendo produzido em nós. Na qualidade de sentimento, o sistema sensório fica muito agudo, como se não tivesse experienciado antes situações similares. Sob o efeito estético, percebe-se como se fosse a primeira vez.

Daqui por diante não sei mais como finalizar o texto. $O$ sentido agora tão frágil, presença tão firme. Quase a mesma 
sensação de quando saímos de um espetáculo. O espetáculo em nós. Parte daquilo se foi, mas outra parte preservou-se. É um entendimento escuro. Quase um estado de elaboração, com a catarse para sintetizar as sensações. Um estado de alívio e demanda. $O$ texto que quer dizer algo, mas não dá conta do sentido que a presença impõe. Momento de pausa. A sensação pede sossego. 


\section{REFERÊNCIAS BIBLIOGRÁFICAS}

GUMBRECHT, Hans Ulrich. Produção de presença: o que o sentido não consegue transmitir. Trad. Ana Isabel Soares. Rio de Janeiro: Contraponto: Ed. PUC-Rio, 2010.

NAVAS, Cássia. Do íntimo, do particular e do público: subsídios para a gestão em dança. Em: Políticas Culturais: reflexões sobre gestão, processos participativos e desenvolvimento. Org. Lia Calabre. Rio de Janeiro: Observatório Itaú Cultural: Casa da Cultura Rui Barbosa/MINC, 2009. Disponível em: http:// cassianavas.com.br/wpcontent/uploads/pdf/do\%20intimo\%20 do\%20particular.pdf Acesso em: 01/09/2014 às 22hoo

Permanente e efêmero, questões e um exemplo da recepção em dança. Este texto é um dos capítulos da publicação "Fruição em Dança". Org. Alba Pedreira Vieira. Visconde do Rio Branco, MG: Ed. Suprema, 2013. (no prelo). Disponível em: http://cassianavas.com.br/wpcontent/uploads/pdf/permanente.pdf. Acesso em: 01/09/2014 às 22hoo 